\title{
New Fuzzy Model for Risk Assessment Based on Different Types of Consequences
}

\author{
K. Karimpour, R. Zarghami*, M.A. Moosavian and H. Bahmanyar \\ Process Design and Simulation Research Center, Oil and Gas Processing Centre of Excellence, School of Chemical Engineering, \\ College of Engineering, University of Tehran, P.O. Box $11155 / 4563$, Tehran - Iran \\ e-mail: rzarghami@ut.ac.ir \\ * Corresponding author
}

\begin{abstract}
A new risk assessment methodology by using fuzzy logic is proposed in this paper. The new Fuzzy Inference System (FIS) was established by the Mamdani algorithm based on different consequences of an incident. A combination of two FIS formed the proposed fuzzy method. Human knowledge and brainstorming were the devices for making the rules and interdependencies between variables in the new model. Different types of consequences and effective parameters were considered as inputs for the first fuzzy inference system. The final consequence was the preliminary result of the first inference model. It added to the probability of failures, as inputs of the second inference model. The result of the second inference model was the risk factor, which was considered as the final output of the proposed new fuzzy model. This model makes risk assessment more convenient in the absence of suitable data. In addition, decision-making will be easier, since its results are more understandable than the results of classical methods. A case study and a comparison between the classic method and the new fuzzy model illustrated that the results of the proposed model are more accurate, reliable and convenient for use in decision-making.
\end{abstract}

Résumé - Nouveau modèle à logique floue pour une évaluation de risque basée sur différents types de conséquences - Une nouvelle méthode d'évaluation des risques en utilisant une logique floue est proposée dans le présent article. Le nouveau système d'inférence flou a été établi en utilisant l'algorithme de Mamdani basé sur les différentes conséquences d'un incident. Une combinaison de deux systèmes d'inférence flous a donné naissance à la méthode floue proposée. Les connaissances humaines et un brainstorming ont été les outils qui ont permis d'établir les règles et interdépendances entre des variables du nouveau modèle. Différents types de conséquences et de paramètres effectifs ont été pris en considération comme entrées pour le premier système d'inférence flou. La conséquence finale qui est le résultat préliminaire du premier modèle d'inférence, est combinée avec la probabilité de risques, en tant qu'entrées du second modèle d'inférence. Cette combinaison conduit à considérer le facteur de risque comme le résultat final du nouveau modèle flou proposé. Ce modèle rend l'évaluation des risques plus facile, en l'absence de données adaptées. En outre, la prise de décision sera plus simple, puisque ses résultats sont plus compréhensibles que les résultats des méthodes classiques. Une étude de cas et une comparaison entre la méthode classique et le nouveau modèle flou ont démontré que les résultats du modèle proposé étaient plus précis, plus fiables et plus faciles à utiliser dans la prise de décision. 


\section{ABBREVIATIONS}

DNV Det Norske Veritas

FIS Fuzzy Inference System

OGP International Association of Oil and Gas Production

OREDA Offshore Reliability Data

RMP Risk Management Process

BLEVE Boiling Liquid Expanding Vapor Explosion

\section{NOMENCLATURE}

$A_{n} \quad$ Hole area

$C_{d} \quad$ Release hole coefficient of discharge

$C A_{i n j}^{f l a m} \quad$ Final probability weighted personnel injury flammable consequence area

$C A_{\text {cmd }}^{\text {flam }}$ Final probability weighted component damage flammable consequence area

$C A_{i n j}^{A I N L} \quad$ Personnel injury flammable consequence area for releases that are not likely to auto-ignition

$C A_{\text {cmd }}^{A I N L}$ Component damage flammable consequence area for releases that are not likely to autoignition

$C A_{\text {cmd }}^{T o x} \quad$ Final probability weighted personnel injury toxic consequence area

$C A_{\text {inj }}^{\text {Leak }} \quad$ Personnel injury non-flammable, non-toxic consequence area for steam and acid leaks

$C A_{\text {cmd }}^{\text {Leak }}$ Component damage non-flammable, non-toxic consequence area for steam and acid leaks

$C A_{i n j}^{n f n t} \quad$ Final probability weighted personnel injury consequence area for non-flammable, non-toxic releases such as steam or acids

$C A_{c m d}^{n f n t}$ Final probability weighted component damage consequence area for non-flammable, non-toxic releases such as steam or acids

$C A_{i n j}^{I N S T}$ Personnel injury flammable consequence area for an instantaneous release

$C A_{c m d}^{I N S T}$ Component damage flammable consequence area for an instantaneous release

$C A_{i n j}^{C O N T}$ Personnel injury flammable consequence area for a continuous release

$C A_{\text {cmd }}^{C O N T}$ Component damage flammable consequence area for a continuous release

fact $^{A I T}$ Auto-ignition temperature consequence area blending factor

fact IC $^{\mathrm{C}}$ Continuous/instantaneous consequence area blending factor determined for each release hole size

gff Generic failure frequency

$g_{c} \quad$ Gravitational constant
$W_{n} \quad$ Theoretical release rate

$K_{v, n} \quad$ Liquid flow viscosity correction factor

$P_{a t m} \quad$ Atmospheric pressure

$P_{s} \quad$ Storage or normal operating pressure

$\rho_{L} \quad$ Liquid density in storage or normal operating conditions

\section{INTRODUCTION}

There are many different definitions of risk in the literature, based on various aspects. The simplest definition of risk was introduced by Hertz and Thomas (1994): a barrier for a successful operation. Jafari (2001) defined risk as the possibility of losses in a project. More complete and deeper definitions were provided by Varnes (1984), Perry and Hayes (1985), Chapman and Ward (1997), Baloi and Price (2003), Pokoradi (2002), Mark et al. (2004), Kirchsteiger (2005) and Darbra et al. (2008a). In spite of various definitions of risk, there are some common features between different sources of risks, which were highlighted by Chia (2006) and Nieto-Morote and Ruz-Vila (2011) as follows:

- risk is a feature concern and event;

- there is no confidence in occurrence of a risk;

- risk shall be an uncertain condition or event that can affect projects' conditions, operations, or goals, if it occurs;

- the probability of a risk must be between $0-100 \%$;

- the impact, consequences, losses, or any other effects of risk must be unplanned.

Hence, risk can be introduced as the existence of inherent uncertainties in systems that affect projects' goals and decrease success due to unpredictable and unplanned probabilities and possibilities. This definition is very useful for being applied in risk assessment by concentrating on uncertainty and probability. In addition, it makes risk a probable factor to be calculated by the study of probabilities and possibilities. In fact, this definition showed that probability and possibility were the basic steps of risk introduction.

To reduce unplanned and undesirable effects of risk during projects and control its level, risk must be managed (Naderi, 2008) by a Risk Management Process (RMP). Like risk sources and aspects, risk management processes consist of different steps, activities and directions. Commonly, risk management includes risk assessment, risk mitigation, risk acceptance and risk communication (API, 2008). Risk assessment is the most important step in risk management (Darbra et al., 2008a), which includes hazard identification, frequency analysis and consequence evaluation. There are many probability-based methods by which risk is assessed but new techniques based on possibility methods were developed since mathematical relations 
and parameters for risk assessment were very difficult to model (Lees, 2001).

Pokoradi (2002) defined the preliminary basis of risk assessments by possibility methods and fuzzy logic. Bowles and Pelaez (1995) evolved the use of fuzzy arithmetic and linguistic variables in risk assessments while characterizing the system reliability. For a period, nuclear engineering systems were assessed through Fuzzy Inference System (FIS), particularly by Guimaraes and Lapa (2007). Karimi and Hüllermeier (2007) suggested a modular framework for risk assessment by fuzzy logic. They used possibility-probability distribution as a new approach for analyzing risks. Markowski and Mannan (2008, 2009a) and Markowski et al. (2009b) developed a risk matrix based on fuzzy thinking and described fuzzification of the frequency and severity of the consequences of an incident scenario as basic inputs for fuzzy risk assessment. In addition, many attempts were made in the models at developing possibility-based risk assessments in environmental issues since there were many uncertainties and lack of information in environmental risk analysis. During the last decade, different applications of fuzzy logic in environmental risk assessment have been discussed in papers. Ma (2002), Dahab et al. (1994), Uricchio et al. (2004), McKone and Deshpande (2005), and Darbra et al. (2008b) established different FIS for evaluating risk in environmental issues. Finally, Kentel and Aral (2007) and Vemula et al. (2004) tried to use a hybrid of probabilistic and fuzzy methods to analyze environmental risks.

Most of the studies mentioned applied a general definition of risk for analyzing by considering the frequency of failure and consequence as risk factors (Lees, 2001; Modarres, 2006). In real situations, each of the frequency and consequence factors is affected by different variables so that inattention to them has major impacts on risk assessment. A study was conducted on the details of consequences in this paper by developing new fuzzy inference systems. Different types of consequences and effective variables on severities were considered as inputs to a consequence model FIS and the final consequence was calculated as output. Then, the final consequence and frequency were entered in the risk model FIS and the final risk factor was calculated by the second FIS. The main objective of this paper is to show the effects of different variables in consequence calculation and decrease uncertainties in risk calculation by fuzzy logic.

\section{THEORY}

\subsection{Fuzzy Logic}

Fuzzy logic is a set of collective functions and relations to assess fuzzy sets (Zadeh, 1965). Fuzzy logic methods have been developed in risk assessment for a decade.
The principle of fuzzy thinking and multi-valued logics has a very long history. Jan Lukasiewicz (Duboise et al., 2007) established the principle of multi-valued logics for the first time in 1920, and Black (1937) developed vagueness and multi-valued logic application to set objects. Finally, Zadeh introduced the first fuzzy sets in 1965 and defined fuzzy sets as sets with a membership function (Zadeh, 1965). Based on Zadeh's description, if $U$ is the universe of discourse $(\mathrm{U}=\{\mathrm{u}\})$, a fuzzy set $(F$ of $U)$ is defined by membership functions as presented by:

$$
\begin{gathered}
\mu_{F}: U \rightarrow[0,1] \\
F=\left\{\left\langle u, \mu_{F}(u) \mid u \in U\right\rangle\right\}
\end{gathered}
$$

where $\mu_{F}(u)$ is the degree of membership of $u$ in $F$, and $\mu_{F}(u)$ will be between 0 and 1 . This description changed the arithmetic methods in different branches of science. Following fuzzy set description, risk studies and assessment methods changed as well. Fuzzy logic was established based on possibility theories (Duboise and Prade, 1990).

In risk studies of a project, fuzzy logic methods are used to answer "How safe is the project?", while classical risk methods answer a different question, "Is the activity safe?" (Markowski et al., 2009b). In addition, some other characteristics make risk assessment by fuzzy logic more applicable than classical methods. The main advantages of fuzzy system usage in risk assessment are considered as follows:

- fuzzy logic risk assessment expresses the possibility of an outcome, but classical risk assessment methods estimate the likelihood of an outcome (Darbra et al., 2008a);

- input and output relationships in fuzzy logic risk assessment are determined not by complicated equations, but by sets of logical rules (Blair et al., 2001);

- fuzzy logic risk assessment can be used for cases with input data that is vague, imprecise and insufficient (Darbra and Casal, 2009);

- results of risk assessment by fuzzy logic are easy for decision-making. In fact, managers can understand results and outgoings better and more precisely;

- partial failures can be studied by fuzzy sets and make it possible to conduct study of risk in more detail and more real conditions.

In spite of the mentioned advantages of fuzzy logic application in risk assessment, there are some disadvantages, on the other hand:

- reliance on subjective inputs (Darbra et al., 2008a);

- complete data sets and complex parameter correlations cause failure (Ferson, 2002);

- the experimental basis of input preparation. 


\subsection{Fuzzy Logic Inference Description}

Fuzzy models and calculating processes include different steps (Fig. 1). As shown, there are three main steps to define a fuzzy system: fuzzification, fuzzy inference and defuzzification (Zadeh, 1965).

\subsubsection{Fuzzification}

Crisp and real values are changed to linguistic functions and fuzzy sets in fuzzification. In fact, the linguistic terms and membership functions are defined based on actual and real values to determine the degree of truth for each assumption. As shown in Figure 1, the output of this step is a fuzzy value. In other words, membership functions are defined in this step to transfer data and values from the classical world to the fuzzy systems (Belohlavek and Klir, 2011).

There are five different types of membership functions: triangular, trapezoidal, Gaussian, singleton and piecewise linear

The most common and popular membership functions were categorized as triangular, trapezoidal and Gaussian types (Markowski and Mannan, 2008; Jamshidi et al., 2012; Wulan and Petrovic, 2012). Suitable types of functions are selected based on experience, knowledge, problem, statements (Grima et al., 2000) and characteristics of variables (Xie, 2003). Triangular and trapezoidal membership functions have the advantage of simplicity. On the other hand, Gaussian membership functions are the most natural (Grima et al., 2000), smooth, and non-zero at all points (Jang and Sun, 1997). Although Gaussian membership functions enjoy the advantages mentioned they are unable to specify asymmetric membership functions (Mamdani, 1976) and it should be considered in type selections. In spite of the all

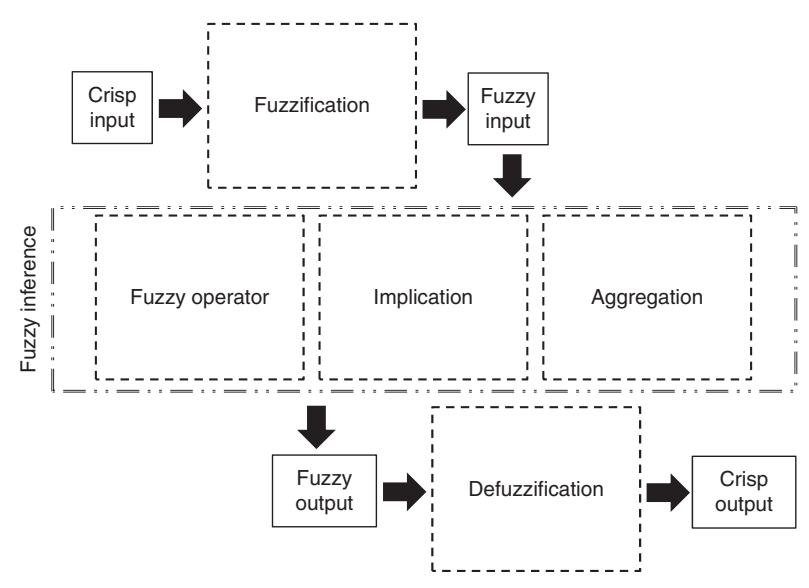

Figure 1

Fuzzy methodology steps. facts mentioned, the types of membership function do not affect the result essentially (Markowski et al., 2009b).

\subsubsection{Fuzzy Inference}

The fuzzy inference step is the most important step in a fuzzy logic process (Mamdani, 1976). The fuzzy inference models consist of three sub-processes: fuzzy operator, implication and aggregation (Li, 2006). These sub-processes use different composition methods to establish a fuzzy model. These compositions are combined by sets of if-then rules, which are obtained from human experience, and synthesize fuzzy inputs into fuzzy outputs.

There are three main different fuzzy inference systems: Mamdani fuzzy models, Sugeno fuzzy models and the Tsukamoto fuzzy inference model (Gentile et al., 2003), that have been used in different studies. Fuzzy operators make different models; hence, aggregation and defuzzifications are different in each model. In fact, these fuzzy models vary in the way outputs are determined (Jang and Sun, 1997).

Mamdani's fuzzy model is the most commonly seen fuzzy inference system (Jamshidi et al., 2012). It uses the fuzzy sets and fuzzy logic concepts to translate linguistic and subjective terms into an algorithm (Mamdani and Assilian, 1975). Different composition methods are used to establish a Mamdani fuzzy model. Max-min composition was used in this paper. It is defined arithmetically as follows:

$$
\begin{gathered}
\mu_{C k}(z)=\max \left[\min \left[\mu_{A k}(\operatorname{input}(x)), \mu_{B k}(\operatorname{input}(y))\right]\right] \\
=1,2, \ldots, r
\end{gathered}
$$

where $\mu_{C k}, \mu_{A k}$, and $\mu_{B k}$ are the membership functions of output " $z$ " for the rule " $k$ ", input " $x$ ", and input " $y$ ", respectively.

\subsubsection{Defuzzification}

The fuzzy set, which was calculated in previous steps, changes to a single number in defuzzification. There are different methods for defuzzifying: center of area, bisector, middle of maximum, largest of maximum and smallest of maximum. Different defuzzification methods are shown in Figure 2, where $\mu$, is the membership function and $Z$ is the universe of discourse.

Perhaps the most popular defuzzification method is the center of area method, which returns the center of the area under the curve (Chiu, 1994). The center of area method uses Equation (4) for defuzzification (Iphar and Goktan, 2006).

$$
Z_{C O A}=\frac{\int_{z} \mu_{A}(z) z \cdot d z}{\int_{z} \mu_{A}(z) \cdot d z}
$$

where $Z_{C O A}$ is the crisp value for the " $z$ " output and $\mu_{A}(z)$ is the output membership function. 


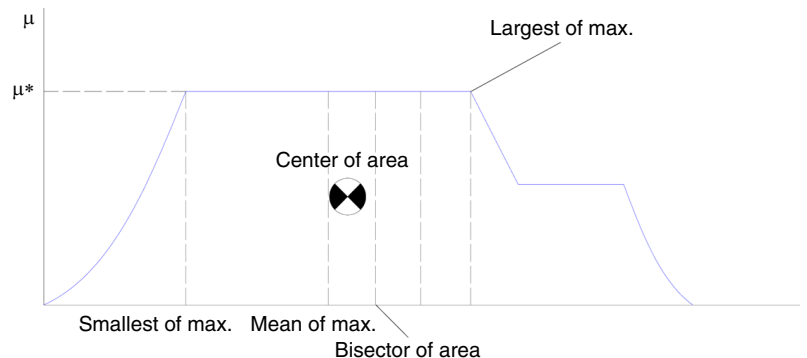

Figure 2

Different methods of defuzzification.

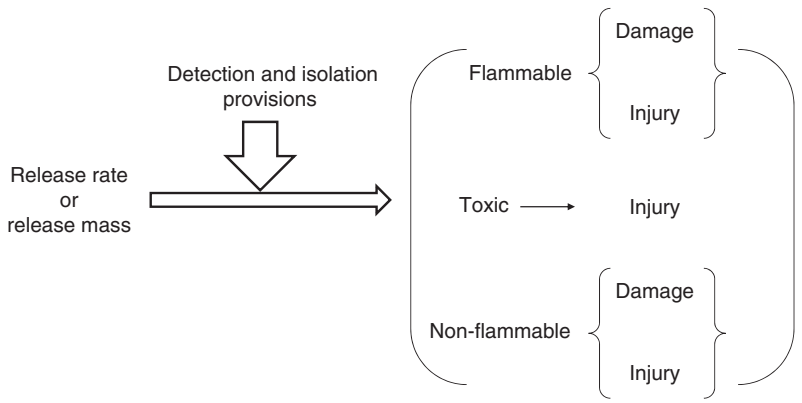

Figure 3

Various consequences for a release/rupture scenario.

\section{RISK ASSESSMENT BY FUZZY LOGIC}

Risk of releases and their probable consequences in a chemical plant were studied by a new method based on fuzzy logic systems. In this paper, a general definition of risk is selected: risk is a combination of the probability of an event and its consequences (Lees, 2001; Markowski et al., 2009b). Indeed, the risk factor is calculated based on the probability of failure (frequency of an event occurrence) and its probable consequences. Most of the methods that were developed recently worked on the probability of occurrences. Unlike previous studies, the consequences and impacts of incidents, which were raised by release of chemical materials in industries, were studied in this paper.

Probabilities were extracted from handbooks and guidelines, such as OREDA, DNV Note 14 and OGP guidelines (OREDA, 2009; DNV, 2006; OGP, 2010).

\subsection{Basis of Fuzzy Modeling}

There are many consequences associated with any release in a plant. Cost impacts, time delay, injury and fatalities, and environmental effects are the main consequences in the case of equipment/pipeline failure (Lees, 2001; Markowski and Mannan, 2008; AIChE/CCPS, 1999; Kletz, 1977).

The type of material released specifies the types of consequences. As shown in Figure 3, release of flammable, toxic and non-flammable material has various consequences. Release of flammable and explosive materials has potential for damaging equipment and personnel injury from thermal radiation and explosion overpressure. Release of nonflammable materials was also considered. Consequences such as chemical splashes and high temperature steam affect personnel health. Moreover, physical explosions and Boiling Liquid Expanding Vapor Explosion (BLEVE) can damage equipment and have personnel injury effects. Toxic material releases cause personnel injury and fatalities due to overexposure of personnel to toxic components and concentrations.

Different equations for calculating consequences are presented in Table 1. As mentioned in this table, complicated mathematical operations shall be done to evaluate different consequences. In addition, many assumptions and data are required to solve any of the provided equations. The required data for calculating the consequences of an event are not ready or easy to access most of the time. These limitations cause many restrictions in the usage of arithmetic and classical methods.

The fuzzy logic model was established based on the Mamdani algorithm as the most popular algorithm (Jamshidi et al., 2012) and the max-min composition method as the most popular method (Ross, 2010), which was used for composite relations. The inputs and outputs which were used to make this FIS are detailed in Figure 4. As shown, two FIS models were established to calculate the risk factor: a consequence model FIS and risk model FIS. As mentioned in Figure 4, the release rate was the first required data with which consequence modeling started. Magnitudes of releases have very important effects on sequential events and final consequences. Different parameters determine release rates: the physical properties of the material, the initial phases, the operating conditions and release hole sizes (API, 2008).

Detection and isolation provisions that decrease the consequence of releasing are considered as one of the FIS inputs (Mamdani and Assilian, 1975). Detection and isolation systems are provided to reduce the effects of a release of hazardous materials. These systems affect the releases in two different ways: detection and isolation systems to reduce the rate and duration, and mitigation systems to reduce the consequences of a release by minimizing ignition possibility or limiting spread of materials. Different types of consequences considered as inputs to the first FIS and final 
TABLE 1

Different equations for calculating consequences

\begin{tabular}{|c|c|c|}
\hline Type of consequence & Equations & Remark \\
\hline \multirow[t]{4}{*}{ Flammable } & $C A_{i n j, n}^{f l a m}=C A_{i n j, n}^{f l a m-A I L} \cdot f a c t^{A I T}+C A_{i n j, n}^{A I N L}\left(1-f a c t^{A I T}\right)$ & \\
\hline & $C A_{c m d, n}^{\text {flam }}=C A_{c m d, n}^{\text {flam-AIL }} \cdot f a c t^{A I T}+C A_{c m d, n}^{A I N L}\left(1-\right.$ fact $\left.^{A I T}\right)$ & \\
\hline & $C A_{i n j}^{\text {flam }}=\frac{\sum_{n=1}^{4} g f f_{n} \cdot C A_{\text {inj,n }}^{\text {flam }}}{g f f_{\text {total }}}$ & \\
\hline & $C A_{c m d}^{\text {flam }}=\frac{\sum_{n=1}^{4} g f f_{n} \cdot C A_{i c m d, n}^{\text {flam }}}{g f f_{\text {total }}}$ & \\
\hline \multirow[t]{5}{*}{ Toxic } & $C A_{i n j, n}^{t o x}=C_{8} \cdot 10\left(c \cdot \log _{10}\left[c_{4} \cdot\right.\right.$ rate $\left.\left._{n}^{t o x}\right]+d\right)$ & For $\mathrm{HF}$ or $\mathrm{H}_{2} \mathrm{~S}$ only \\
\hline & $C A_{i n j, n}^{t o x}=C_{8} \cdot 10\left(c \cdot \log _{10}\left[c_{4} \cdot\right.\right.$ mass $\left.\left._{n}^{t o x}\right]+d\right)$ & $C_{8}, c, C_{4}$ and $d$ are constants \\
\hline & $C A_{i n j, n}^{t o x}=e\left(\text { rate }_{n}^{t o x}\right)^{f}$ & For ammonia or chlorine \\
\hline & $C A_{i n j, n}^{t o x}=e\left(\operatorname{mass}_{n}^{t o x}\right)^{f}$ & $e$ and $f$ are constants \\
\hline & $C A_{i n j}^{t o x}=\frac{\sum_{n=1}^{4} g f f_{n} \cdot C A_{i n j, n}^{t o x}}{g f f_{\text {total }}}$ & \\
\hline \multirow[t]{4}{*}{ Non-flammable-non-toxic } & $C A_{i n j, n}^{l e a k}=C A_{i n j, n}^{I N S T} \cdot f a c t^{I C}+C A_{i n j, n}^{C O N T}\left(1-\right.$ fact $\left._{n}^{I C}\right)$ & \\
\hline & $C A_{c m d, n}^{\text {leak }}=C A_{c m d, n}^{I N S T} \cdot$ fact $^{I C}+C A_{c m d, n}^{C O N T}\left(1-\right.$ fact $\left._{n}^{I C}\right)$ & \\
\hline & $C A_{\text {inj }}^{\text {nfnt }}=\frac{\sum_{n=1}^{4} g f f_{n} \cdot C A_{\text {inj, } n}^{\text {leak }}}{g f f_{\text {total }}}$ & \\
\hline & $C A_{c m d}^{\text {flam }}=\frac{\sum_{n=1}^{4} g f f_{n} \cdot C A_{c m d, n}^{\text {leak }}}{g f f_{\text {total }}}$ & \\
\hline
\end{tabular}

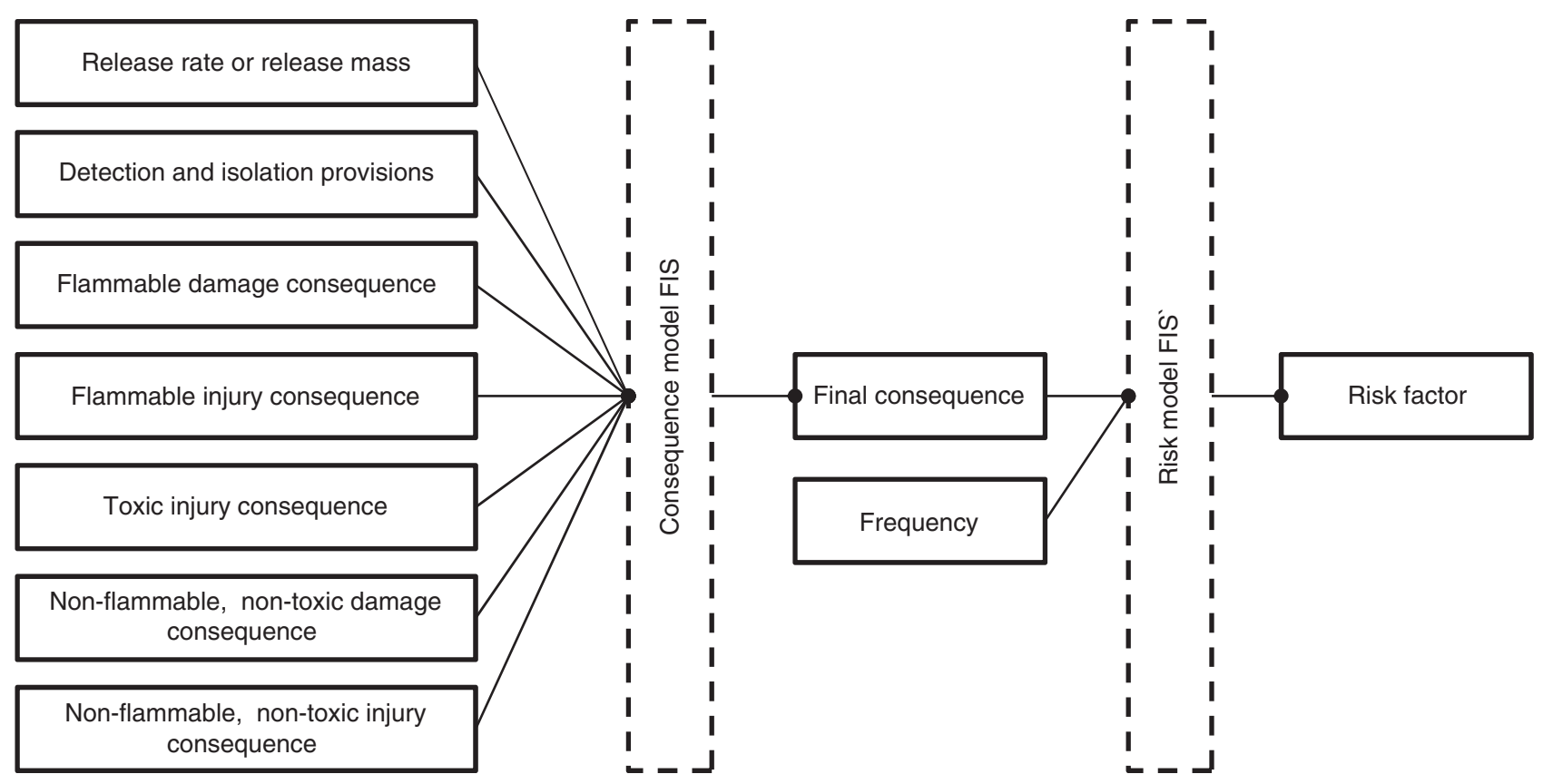

Figure 4

FIS configuration. 
consequence were the results of the consequence model FIS. A combination of the final consequence and frequency in the second FIS resulted in a risk factor for each release incident.

\subsection{Establishment of Fuzzy Model}

To create FIS, fuzzification was the first step. The Gaussian type of membership functions were used for consequence inputs and outputs, since they were the most natural (Markowski and Mannan, 2009b), non-zero and smooth functions at all points (Xie, 2003). The Gaussian membership functions are based on the following equation:

$$
\operatorname{Gaussian}(x: c, \sigma)=e^{-\frac{1}{2}\left(\frac{x-c}{\sigma}\right)^{2}}
$$

where $c$ is the center and $\sigma$ is the width of the membership function.

The Gaussian functions have between $45-55 \%$ overlapping to make sure that there is no hole (Jamshidi et al., 1997).

Frequencies were fuzzified by trapezoidal membership functions since they reflect the best failure data based on experience (Markowski and Mannan, 2008). The trapezoidal membership function depends on four parameters $a, b, c$ and $d$, as given by Equation (6). The parameters $a$ and $d$ show the "feet" and the trapezoid; the parameters $b$ and $c$ locate the "shoulders".

$$
\text { Trapezoidal }(x, a, b, c, d)=\left\{\begin{array}{cc}
0 & x \leq a \\
\frac{(x-a)}{(b-a)} & a \leq x \leq b \\
1 & b \leq x \leq c \\
\frac{(d-x)}{(d-c)} & c \leq x \leq d \\
0 & d \leq x
\end{array}\right.
$$

The values of fuzzifying membership functions for inputs and outputs of both FIS are presented in Table 2 .

As presented in Table 2, the universe of discourse for consequence variables was between zero and 100 to cover the percentage of impacts. Various membership functions are entitled and characterized in Table 2 based on types of consequence variables. The universe of discourse for frequencies was selected based on experience, general guidelines and standards (OREDA, 2009; DNV, 2006; OGP, 2010). It is detailed in membership functions to cover very rare circumstances and most credible events.

TABLE 2

\begin{tabular}{|c|c|c|c|c|}
\hline \multicolumn{5}{|c|}{ Gaussian membership function } \\
\hline Variable & Universe of discourse & Membership functions & $C$ & $\sigma$ \\
\hline \multirow{5}{*}{$\begin{array}{l}\text { Release rate or release } \\
\text { mass }\end{array}$} & \multirow[t]{5}{*}[\begin{array}{ll}{0}&{100}\end{array}]{} & Very small & 0 & 10 \\
\hline & & Small & 25 & 10 \\
\hline & & Medium & 50 & 10 \\
\hline & & Large & 75 & 10 \\
\hline & & Very large & 100 & 10 \\
\hline \multirow{5}{*}{$\begin{array}{l}\text { Detection and isolation } \\
\text { provisions }\end{array}$} & \multirow[t]{5}{*}[\begin{array}{ll}{0}&{100}\end{array}]{} & Perfect operation & 0 & 10 \\
\hline & & Good operation & 25 & 10 \\
\hline & & Medium operation & 50 & 10 \\
\hline & & Weak operation & 75 & 10 \\
\hline & & Very weak operation & 100 & 10 \\
\hline \multirow{5}{*}{$\begin{array}{l}\text { Flammable damage } \\
\text { consequence }\end{array}$} & \multirow[t]{5}{*}[\begin{array}{ll}{0}&{100}\end{array}]{} & No damage & 0 & 10 \\
\hline & & $\begin{array}{c}\text { Self equipment } \\
\text { devastation/damage }\end{array}$ & 25 & 10 \\
\hline & & $\begin{array}{l}\text { Beside equipment } \\
\text { devastation/damage }\end{array}$ & 50 & 10 \\
\hline & & Unit devastation/damage & 75 & 10 \\
\hline & & Plant devastation/damage & 100 & 10 \\
\hline
\end{tabular}

Values of membership functions 
TABLE 2 (continued)

\begin{tabular}{|c|c|c|c|c|}
\hline \multicolumn{5}{|c|}{ Gaussian membership function } \\
\hline Variable & Universe of discourse & Membership functions & $C$ & $\sigma$ \\
\hline \multirow{3}{*}{$\begin{array}{l}\text { Flammable injury } \\
\text { consequence }\end{array}$} & \multirow[t]{3}{*}[\begin{array}{ll}{0}&{100}\end{array}]{} & No injury consequence & 0 & 21 \\
\hline & & Injury of personnel & 50 & 21 \\
\hline & & Death of personnel & 100 & 21 \\
\hline \multirow[t]{3}{*}{ Toxic injury consequence } & \multirow[t]{3}{*}[\begin{array}{ll}{0}&{100}\end{array}]{} & No injury consequence & 0 & 21 \\
\hline & & Injury of personnel & 50 & 21 \\
\hline & & Death of personnel & 100 & 21 \\
\hline \multirow{5}{*}{$\begin{array}{l}\text { Non-flammable-non-toxic } \\
\text { damage consequence }\end{array}$} & \multirow[t]{5}{*}[\begin{array}{ll}{0}&{100}\end{array}]{} & No damage & 0 & 10 \\
\hline & & $\begin{array}{c}\text { Self equipment } \\
\text { devastation/damage }\end{array}$ & 25 & 10 \\
\hline & & $\begin{array}{l}\text { Beside equipment } \\
\text { devastation/damage }\end{array}$ & 50 & 10 \\
\hline & & Unit devastation/damage & 75 & 10 \\
\hline & & Plant devastation/damage & 100 & 10 \\
\hline \multirow{3}{*}{$\begin{array}{l}\text { Non-flammable-non-toxic } \\
\text { injury consequence }\end{array}$} & \multirow[t]{3}{*}[\begin{array}{ll}{0}&{100}\end{array}]{} & No injury consequence & 0 & 21 \\
\hline & & Injury of personnel & 50 & 21 \\
\hline & & Death of personnel & 100 & 21 \\
\hline \multirow[t]{5}{*}{ Final consequence } & \multirow[t]{5}{*}[\begin{array}{ll}{0}&{100}\end{array}]{} & Insignificant & 0 & 10 \\
\hline & & Minor & 25 & 10 \\
\hline & & Moderate & 50 & 10 \\
\hline & & Major & 75 & 10 \\
\hline & & Catastrophic & 100 & 10 \\
\hline \multirow[t]{6}{*}{ Risk factor } & \multirow[t]{6}{*}[\begin{array}{ll}{-9}&{0}\end{array}]{} & Low risk & -9 & 0.76 \\
\hline & & Negligible risk & -7.2 & 0.76 \\
\hline & & Tolerable risk & -5.4 & 0.76 \\
\hline & & Undesirable risk & -3.6 & 0.76 \\
\hline & & Intolerable risk & -1.8 & 0.76 \\
\hline & & High risk & 0 & 0.76 \\
\hline
\end{tabular}

Trapezoidal membership function

\begin{tabular}{c|c|c|c|c|c|c}
\hline \multirow{2}{*}{ Variable } & Universe of discourse & Membership functions & $a$ & $b$ & $d$ & $c$ \\
\hline \multirow{2}{*}{ Frequency } & \multirow{2}{*}[-80]{} & Impossible & -9.43 & -8.15 & -7.83 & -6.55 \\
\cline { 3 - 7 } & & Improbable & -7.86 & -6.58 & -6.26 & -4.98 \\
\cline { 3 - 7 } & & Remote & -6.24 & -4.96 & -4.64 & -3.36 \\
\cline { 3 - 7 } & & Occasional & -4.64 & -3.36 & -3.04 & -1.76 \\
\cline { 3 - 6 } & & Probable & -3.04 & -1.76 & -1.44 & -0.16 \\
\cline { 3 - 6 } & & Frequent & -1.45 & -0.17 & -0.15 & 1.43 \\
\hline
\end{tabular}



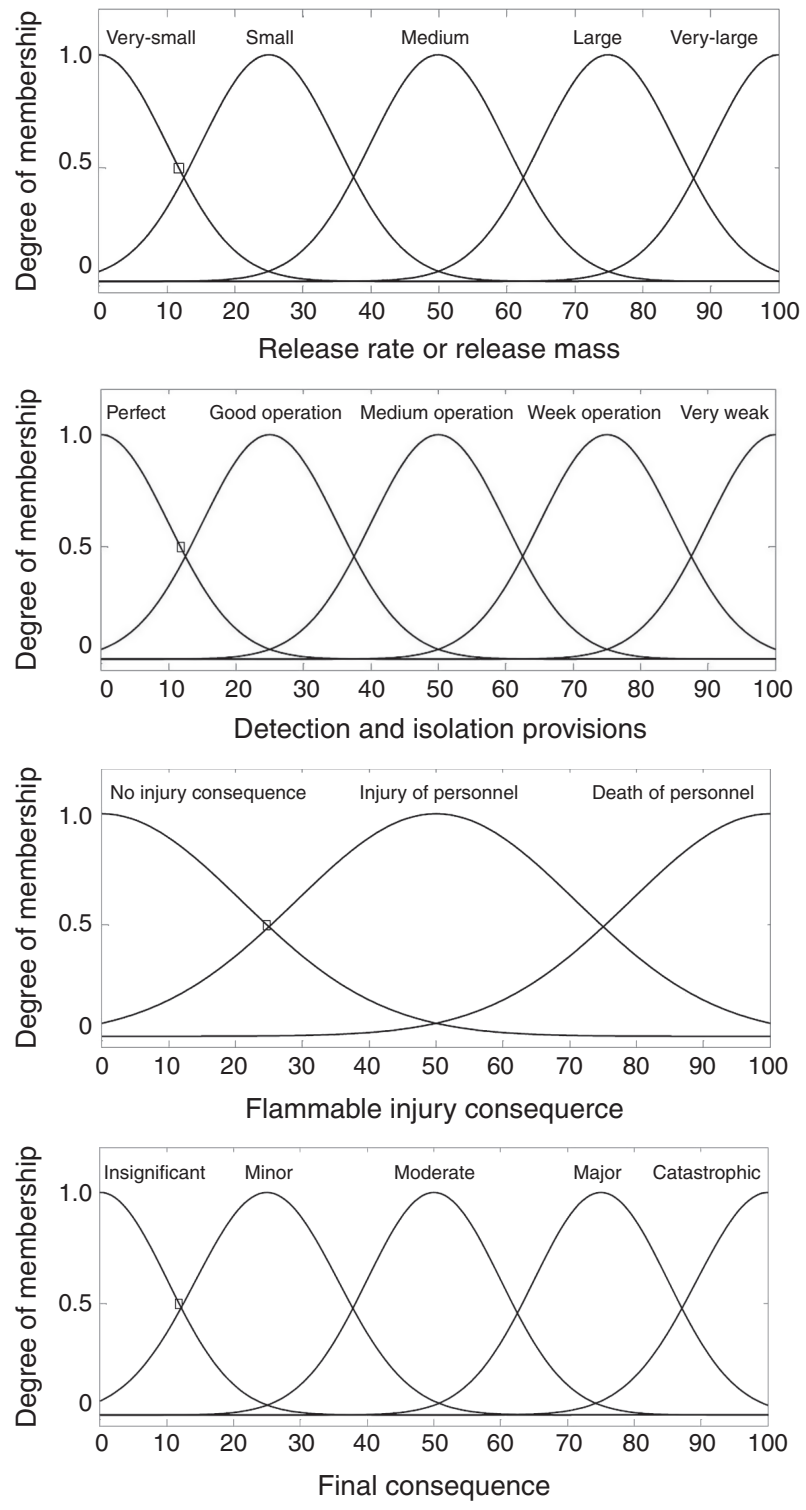

Figure 5

Example of membership functions for the consequence model FIS.

Inputs, outputs curves and examples of the membership functions of the consequence model FIS and risk model FIS are shown in Figures 5 and 6. As shown in Figure 5, all consequence variables were Gaussian type and covered all the universe of discourse based on the values presented in Table 2. In addition, as shown, both inputs and outputs were fuzzy statements based on the Mamdani model. On the other hand, frequency membership functions were selected as logarithmic values in trapezoidal curves, as shown in Figure 6.

The second step to establish a FIS was making if-then rules based on human knowledge. These rules, which were
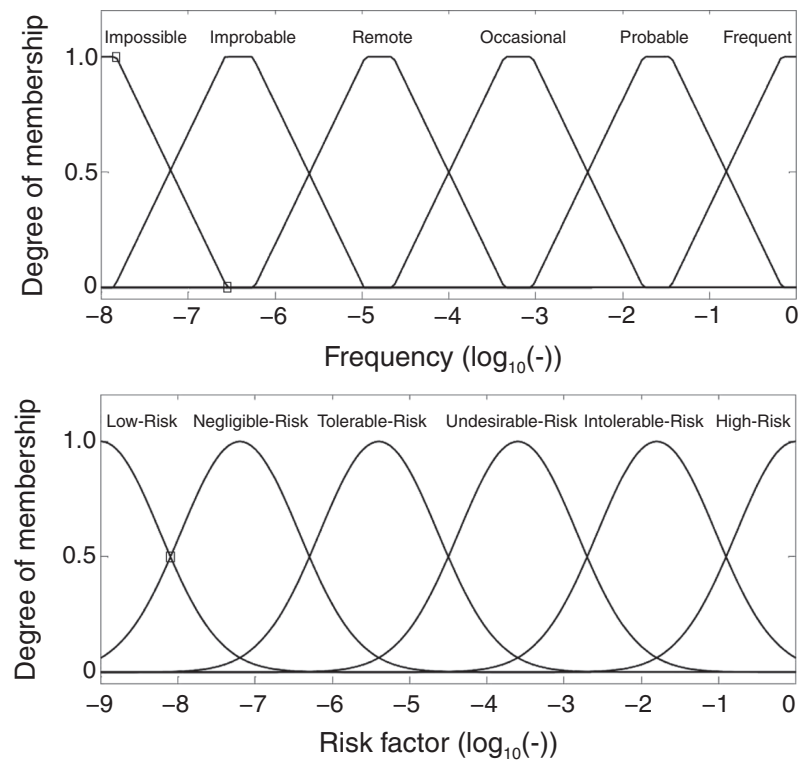

Figure 6

Membership functions for the risk model FIS.

made by expert knowledge during brainstorming meetings, defined the relations between fuzzy inputs and outputs. Brainstorming meetings were held with the participating operating HSE engineer, operating process engineer, operating manager, process-safety design engineer, process design engineer, piping design engineer, instrument design engineer and project design manager. About 116 rules connected inputs and outputs in the first FIS. For instance, one of the rules that was made in the first FIS was: if 'release rate' is small and detection and isolation is very weak and 'flammable damage' is no damage then 'final consequence' is minor.

In the first FIS, the final consequence was the target point resulting from different logics and linguistic terms, originated by human knowledge and experiments. The validation and accuracy of the consequence model FIS was much better than existing FIS for assessing consequences. The new FIS analyzes consequences by concentrating on details of reasons for developing or decreasing release circumstances. In addition, different types of damage and injuries, which may occur during a release, were considered in rule-making. The items mentioned made the consequence model FIS more accurate for calculating consequence factors in comparison with the recommended general risk assessment methods (Markowski and Mannan, 2008; Ma, 2002) and suggested piping risk assessment method (Jamshidi et al., 2012). More than 30 rules connected the variables of the risk model FIS together. An example of the rules that were provided in 


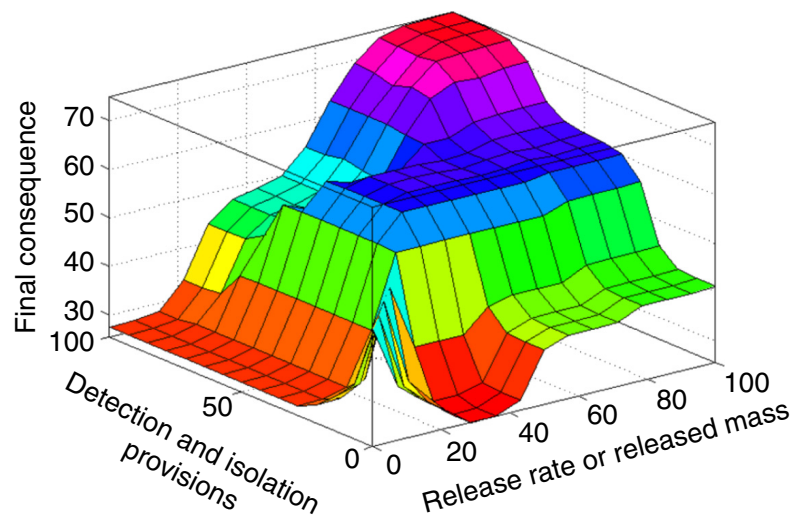

used in this paper for defuzzification (Gottwald, 2006; Crowl and Louvar, 2001).

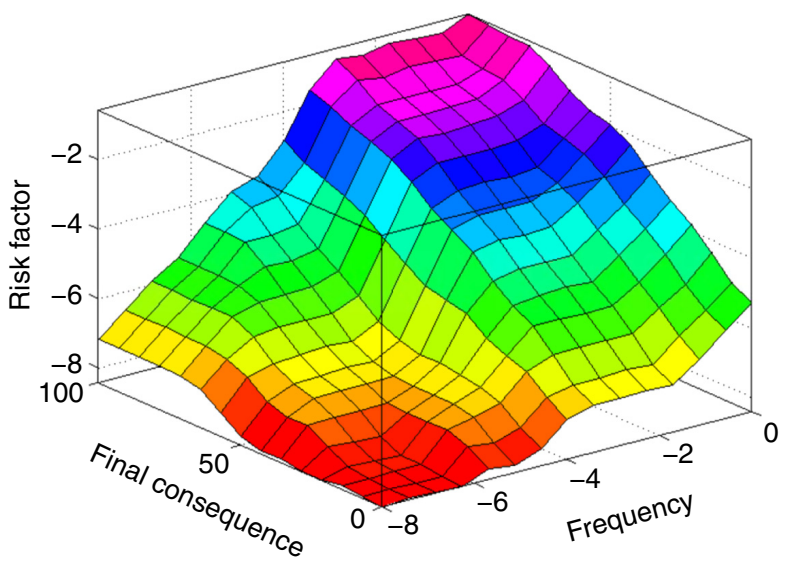

\section{CASE STUDY}

Application of the proposed fuzzy model for calculating risk was checked in this section by studying a gas pipeline between a gas plant and an export jetty. The pipeline, $7 \mathrm{~km}$ length, was routed to the jetty through a general unmanned area and the last $1 \mathrm{~km}$ of this pipeline crossed next to a general warehouse where non-flammable materials were stored. Operators were working $12 \mathrm{~h}$ a day in the warehouse. The general specification of the gas pipeline is presented in Table 3.

As this table shows, liquid propane flows through $24^{\prime \prime}$ - diameter pipe at high pressure and in low temperature conditions. Risk of personnel injury due to flammable material releases from the gas pipeline was studied here by two different methods: the new fuzzy method proposed in this paper and the classical method normally used in such studies. Risk calculations were carried out for a $25-\mathrm{mm}$ leak hole and full-bore rupture as examples. The procedure of the classical method for risk calculation is shown in Figure 8. As shown, the first step for starting risk calculation was selecting the release hole size. Among common leak holes, 25-mm and full-bore release holes were selected as examples Figure 7

Interdependency of variables for the consequence and risk models' FIS.

the risk model FIS was: if 'final consequence' is insignificant and 'frequency' is impossible then 'risk factor' is low risk.

Different rules studied various states of consequences and probability of occurrences for assessing risk factors in a circumstance. It was implemented by using human knowledge and very simple linguistic terms which made fuzzy inference more convenient to understand and analyze. The final risk factor was calculated by considering both FIS in a series run.

The interdependency of different variables for both FIS is shown in Figure 7. There was different interdependency between different variables in the FIS, some of which are shown in Figure 7. This interdependency showed that any change in variables, even minor, would affect the final graph and risk factor. In addition, it illustrated that rule configuration was noticeably effective to provide an acceptable risk assessment method.

In the last step, the defuzzification process was carried out to transfer data from fuzzy values to crisp ones. The center of area method, which is one of the most common ways, was of risk calculations (API, 2008). Calculation of the release rate was the next step, which was done based in the equation mentioned in Figure 8. Since there were different hole sizes, various release rates were calculated, as mentioned in Table 4 $\left(W_{n}\right)$. As the third step, the impacts of detection and isolation systems on reduction of the release magnitude were studied. The reduction factor was extracted from standard tables based on the types of detection and isolation systems. The detection type for the gas pipeline was visual detection,

TABLE 3

Pipeline operational conditions

\begin{tabular}{c|c}
\hline Composition & Propane \\
\hline Size & $24^{\prime \prime}$ \\
\hline Phase & $\mathrm{L}$ \\
\hline Temperature $\left({ }^{\circ} \mathrm{C}\right)$ & -31.7 \\
\hline Pressure $(\mathrm{bar})$ & 25.1 \\
\hline Vol. flow $\left(\mathrm{m}^{3} / \mathrm{h}\right)$ & 54.7 \\
\hline Density $\left(\mathrm{kg} / \mathrm{m}^{3}\right)$ & 577.7 \\
\hline $\mathrm{MW}$ & 44.2 \\
\hline
\end{tabular}


2) Calculate the release rate from equation below:

1) Select the release hole size

$$
w_{n}=C_{d} \cdot k_{v, n} \cdot \rho_{L} \frac{A_{n}}{C_{1}} \sqrt{\frac{2 g_{c}\left(P_{s}-P_{a t m}\right)}{\rho_{L}}}
$$

in above equation viscosity correction is calculated by:

$$
k_{n, v}=\left[0.9935+\frac{2.878}{\mathrm{Re}^{0.5}}+\frac{342.75}{\mathrm{Re}^{1.5}}\right]^{-1.0}
$$

Also, $C_{d}$ is considered to be 0.61 as a conservative assumption

3) Estimate the impacts of detection and isolation systems on release magnitude.

It has reduction impacts on release rate/mass. The reduction factor can be extracted from standard tables.

Type of detection for the gas pipeline is visual detection, cameras or detectors with marginal coverage.

Also, isolation dependent on manually operated valves is considered as a type of isolation system.

Hence, the reduction factor is assumed zero to be zero based on the API standard table 5.8

$$
\begin{aligned}
& C A=a(\text { rate of mass })^{b}, a_{c 3}=313.6, b_{c 3}=1.00 \\
& \text { fact }^{\prime C}=\min \left[\left\{\frac{\text { rate }, 1.0}{C_{5}}\right\}\right] \\
& C A_{i n j, n}^{f l a m}=C A_{i n j, n}^{f l a m-A l L} \cdot f a c t^{A I T}+C A_{i n j, n}^{A I N L} \cdot\left(1-\text { fact }^{A / T}\right) \\
& C A_{\text {cmd }}^{\text {flam }}=\frac{\sum_{n=1}^{4} g f f_{n} \cdot C A_{c m d, n}^{f l a m}}{g f f_{\text {total }}}
\end{aligned}
$$

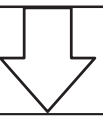

5) Estimate likelihood of personnel presence in consequence area

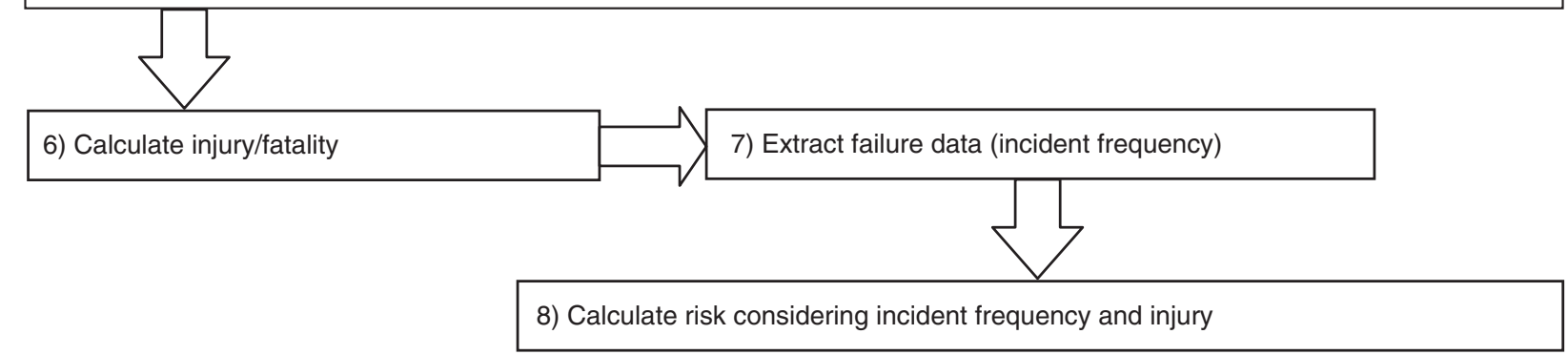

Figure 8

Procedure of risk calculation by the classical method. 
TABLE 4

Results of risk calculation by the classical method and proposed new FIS

\begin{tabular}{|c|c|c|}
\hline \multicolumn{3}{|l|}{ Classical method } \\
\hline Release hole size & $25 \mathrm{~mm}$ & Full bore \\
\hline $\mathrm{Wn}(\mathrm{kg} / \mathrm{s})$ & 13.2 & 4182.35 \\
\hline $\mathrm{CA}^{\mathrm{Inj}}\left(\mathrm{m}^{2}\right)$ & 1600 & 270400 \\
\hline Likelihood of presence of personnel & 0.5 & 0.5 \\
\hline Injury/fatality probability & $3.4 \times 10^{-2}$ & 0.8 \\
\hline Failure data (per year) & $2.4 \times 10^{-6}$ & $6.5 \times 10^{-5}$ \\
\hline Risk (per year) & $8.3 \times 10^{-8}$ & $1.2 \times 10^{-4}$ \\
\hline \multicolumn{3}{|l|}{ Proposed new fuzzy system } \\
\hline Release mass/release rate & 45 & 88 \\
\hline Detection and isolation & 90 & 90 \\
\hline Flammable injury consequence & 30 & 80 \\
\hline Final consequence & 30 & 80 \\
\hline Frequency & -5.62 & -4.187 \\
\hline Risk factor (per year) & -7.12 & -4 \\
\hline
\end{tabular}

cameras or detectors with marginal coverage. Isolation of the pipeline depended on manually operated valves that were considered as types of isolating systems. Hence, the reduction factor was assumed to be zero for the gas pipeline based on the API standard table 5.8 (API, 2008). The fourth step for classical risk calculation was determining consequences. The area involved where personnel may be affected by sequential events of a release was specified in this step $\left(C A^{I n j}\right)$.

The fifth step was estimating the likelihood of the presence of personnel in the consequence area. Based on the storage operator's report, the likelihood of personnel presence in the area of the pipeline was $50 \%$ (POGC, 2010). Hence, fatality and injury calculations were done based on the reported values as the sixth step. Incident frequency calculation was done by extracting failure data from guidelines, and finally, risk was calculated considering incident frequency and injury.

Furthermore, risk of leak/release from the gas pipeline was calculated by the proposed fuzzy system. The graphical rules for calculating risk by the risk model FIS are shown in Figure 9. As shown, the final consequence value was calculated by the first fuzzy inference system as an input for the second fuzzy inference system. A combination of the frequency and final consequence formed the risk factor in the second fuzzy inference system.
The input data, calculated values, and results for both the classical method and the proposed new fuzzy system are presented in Table 4. This table contains two independent parts. The first part shows the calculated parameters and values based on the classical procedure for calculating risk. As shown in Table 4, the fundamental values for calculating risk in the classical procedure were quantitative values, which were calculated based on the complicated equations described in Figure 8 and Table 1. Moreover, the second part of Table 4 shows the input variables for calculating risk by the proposed fuzzy inference system. As mentioned, the input data for the new fuzzy system were linguistic terms that were produced by human knowledge and experiments that were easy to understand and easy to use in decision-making. For instance, based on decisions that were made during meetings of experts, the following inputs were considered for calculating the risk factor by the proposed new fuzzy system in the case of a $25-\mathrm{mm}$ leak hole: release mass/release rate: medium; detection and isolation: weak operation or very weak; flammable injury consequence by considering the results of simulations and magnitude of the release rate: no injury or fatalities of personnel; frequency based on guidelines: remote and improbable. Considering the inputs mentioned, the final consequence was calculated as a minor or moderate consequence. Eventually, the risk factor was calculated 


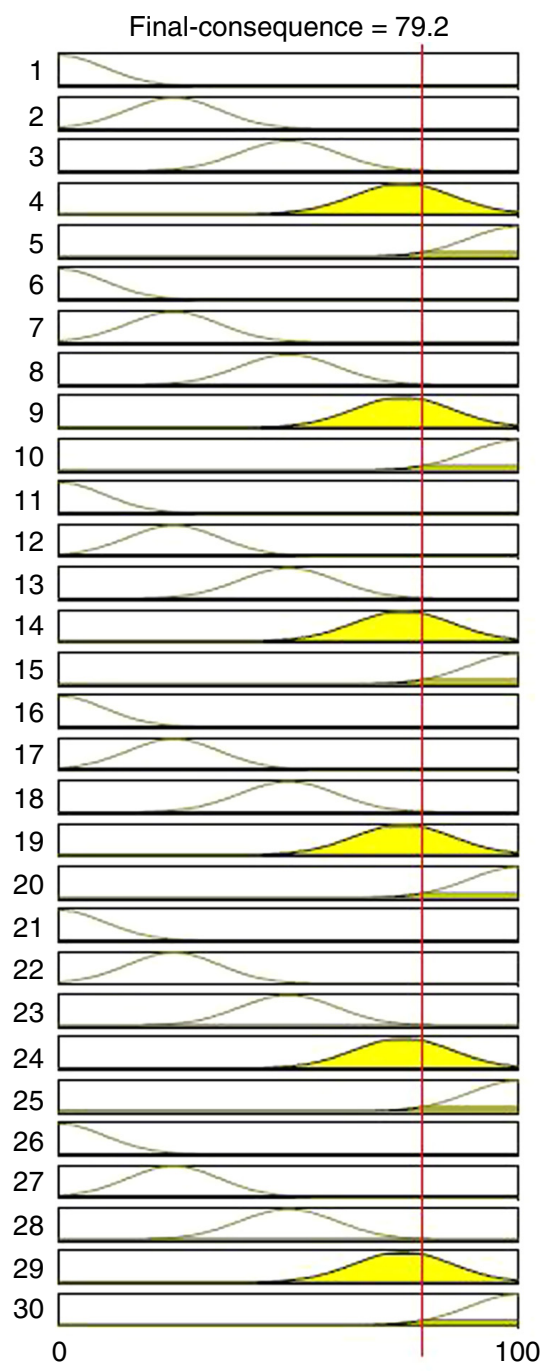

100

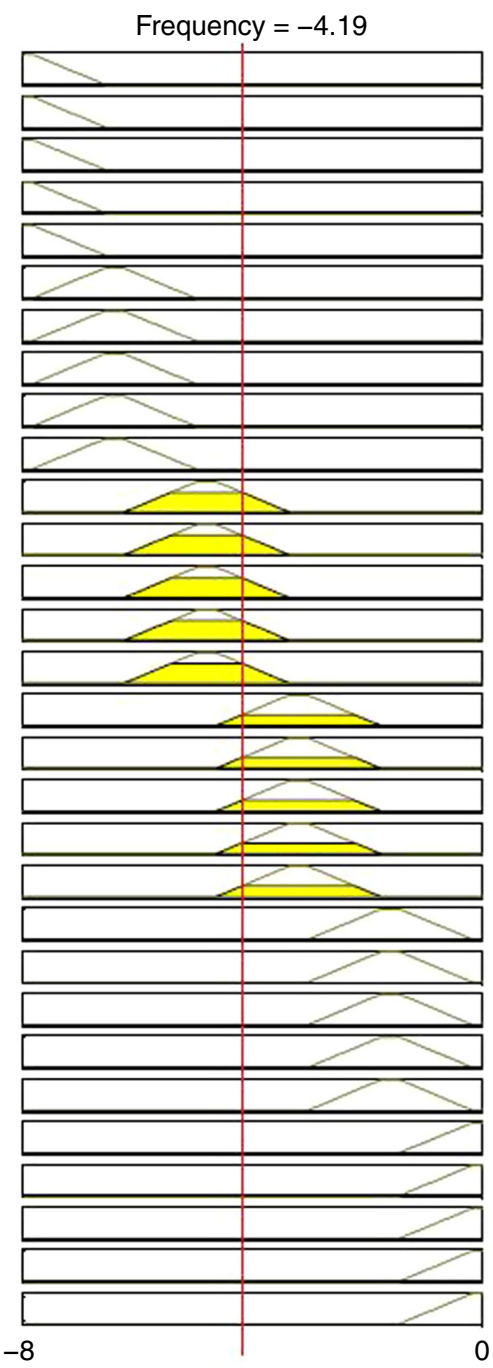

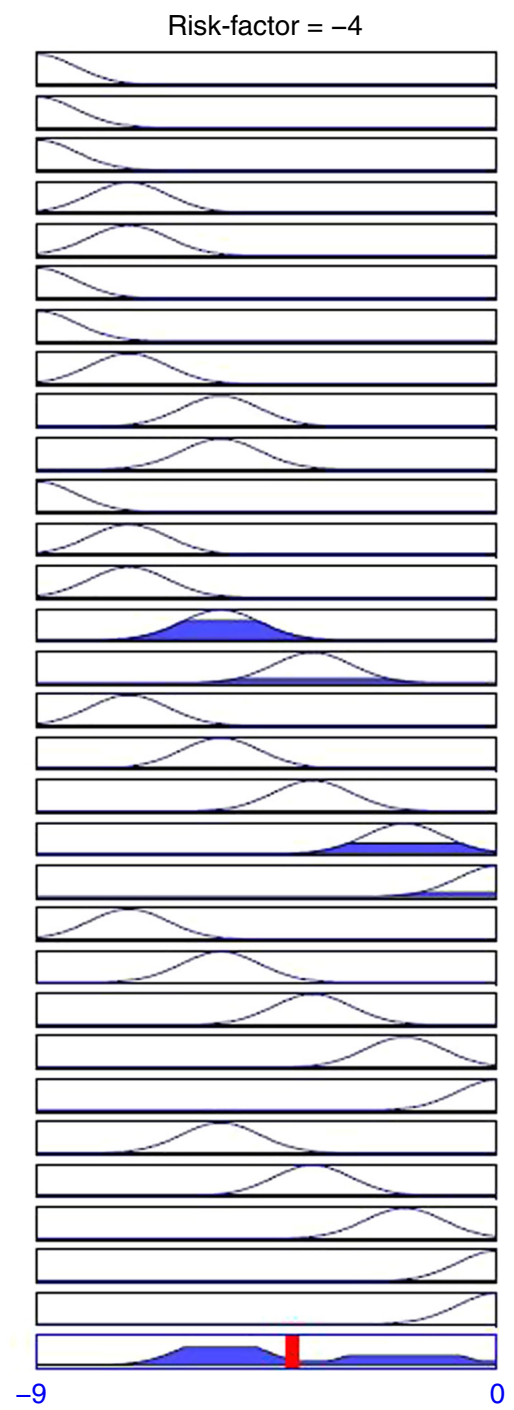

Figure 9

Graphical rules for the risk model FIS.

based on the final consequence and frequency as a negligible risk.

All values that were used for calculating the risk are presented in Table 4 for both the classical and new fuzzy methods. As presented, the proposed fuzzy inference system demonstrated that risk of release from a $25-\mathrm{mm}$ hole was positioned in a negligible risk area and was not considerable. It was certified by the classical method calculation for a leak hole of small diameter, since the calculated risk was very low in comparison with the standard risk criteria (IP 323, 1998). On the other hand, based on the calculated value by the new fuzzy inference system, the risk of full-bore rupture was $80 \%$ undesirable and $20 \%$ tolerable. It was certified again by the classical method, since the calculated risk was considerable and high in comparison with the risk criteria.

A comparison between the calculated risks demonstrated that there was $15 \%$ difference between the result of the proposed new FIS and the classical method.

\section{CONCLUSION}

The risk factor was calculated by a combination of two FIS in this work. A combination of a consequence model FIS and risk model FIS made up the new FIS based on different possible consequences of an incident. The most 
important advantage of the proposed fuzzy system was its comprehensiveness for considering the effects of incidents. In addition, the proposed system has other advantages, presented as follows:

- the relation between inputs and outputs were linguistic terms. It made the model more flexible for changing in different conditions;

- it made the decision-making process simpler and faster, since its results were more understandable and reliable;

- the case study showed that the proposed model has more realistic results than the classical methods. A study of different types of consequences and various variables that affect the consequences of an event showed that risk assessment by the new model was more reliable than classical methods, in which the effects of very important items such as detection and isolation are normally ignored during risk assessments. In addition, brainstorming of experts to estimate parameters gave results based on experimental outcomes. A fuzzy mathematical method also decreases uncertainties and increases accuracy;

- simplicity in the use of this model made it convenient for users throughout complicated risk assessments. In addition, it was a very useful method while suitable data for assessing risk were not accessible.

\section{REFERENCES}

AIChE/CCPS (1999) Guidelines for Consequence Analysis of Chemical Releases, The Center for Chemical Process Safety of the American Institute of Chemical Engineers Publishers, New York.

API (2008) Recommended Practice 581, Risk based inspection technology, Part 3: Consequence analysis in an API RBI assessment, 2nd ed., American Petroleum Institute, Washington DC.

Baloi D., Price A.D.F. (2003) Modeling global risk factors affecting construction cost performance, International Journal of Project Management 21, 261-269.

Belohlavek R., Klir G. (2011) Concepts and fuzzy logic, The MIT Press, Massachusetts.

Black M. (1937) Vagueness: An exercise in logical analysis, Philosophy of Science 4, 427-455.

Blair A.N., Ayyub B.M., Bender W.J. (2001) Fuzzy stochastic riskbased decision analysis with the mobile offshore base as a case study, Marine Structures 14, 69-88.

Bowles J.B., Pelaez C.E. (1995) Application of fuzzy logic to reliability engineering, Proceeding of IEEE 83, 3, 435-449.

Chapman C.B., Ward S.C. (1997) Project risk management: process techniques and insights, John Wiley and Sons, New York.

Chia S.E. (2006) Risk assessment framework for project management, 2006 IEEE International Engineering Management Conference, 17-20 Sept, Bahia, pp. 376-379.

Chiu S. (1994) Fuzzy model identification based on cluster estimation, Journal of Intelligent and Fuzzy Systems 2, 3-10.
Crowl D.A., Louvar J.F. (2001) Chemical Process Safety: Fundamentals with Applications, 2nd ed., Prentice Hall, Englewood Cliffs, New Jersey.

Dahab M.F., Lee Y.W., Bogardi I. (1994) A rule based fuzzy set approach to risk analysis of nitrate contaminated groundwater, Water Science and Technology 7, 45-52.

Darbra R.M., Eljarrat E., Barcelo D. (2008a) How to measure uncertanties in environmental risk assessment, Trends in Analytical Chemistray 27, 377-387.

Darbra R.M., Demichela M., Mure S. (2008b) Preliminary risk assesment of ecotoxic substances accidental releases in major risk installations through fuzzy logic, Process Safety and Environmental Protection 86, 103-111.

Darbra R.M., Casal J. (2009) Environmental risk assessment of accidental releases in chemical plants through fuzzy logic, Chemical Engineering Transactions 17, 287-292.

DNV (2006) Report No. T14: Technical note process equipment failure frequencies.

Duboise D., Esteva F., Godo L., Prade H. (2007) Fuzzy set based logics- an history oriented presentation of their main development. Handbook of the History of Logic, Vol. 8, Elsevier, New York.

Duboise D., Prade H. (1990) Resolution principles in possibilistic logic, International Journal of Approximate Reasoning 4, $1-21$.

Ferson S. (2002) RAMAS Risk calc 4.0 software: risk assessment with uncertain numbers, Lewis publishers, Boca Raton.

Gentile M., Rogers W.J., Mannan M.S. (2003) Development of a fuzzy logic-based inherent safety index, ICHEM Journal 81, 444-456.

Gottwald S. (2006) Universes of fuzzy sets and axiomatizations of fuzzy set theory. Part I: Model-based and axiomatic approaches, Studia Logica 82, 211-244.

Grima M.A., Bruines P.A., Verhoef P.N.W. (2000) Modeling tunnel boring machine performance by nuero fuzzy methods, Tunneling and Underground Space Technology 15, 259-269.

Guimaraes A.C.F., Lapa C.M.F. (2007) Fuzzy inference to risk assessment on nuclear engineering systems, Applied Soft Computing 7, 17-28.

Hertz D.B., Thomas H. (1994) Risk analysis and its applications, 2nd ed., John Wiley and Sons, New York.

IP 323 (1998) A Risk-Based Approach to Hazardous Area Classification, The Institute of Petroleum, London.

Iphar M., Goktan R.M. (2006) An application of fuzzy sets to the diaggability index rating method for surface mine equipment selection, International Journal of Rock Mechanicas and Mining Science 43, 253-266.

Jafari A. (2001) Management of risk, uncertainties and opportunities on projects: time for fundamental shift, International Journal of Project Management 19, 89-101.

Jamshidi A., Jang J.S.R., Sun C.T., Mizutani E. (1997) Neural fuzzy and soft computing, Prentice Hall, Englewood Cliff, New Jersey.

Jamshidi A., Yazdani A., Yakhchali S., Khaleghi S. (2012) Developing a new fuzzy inference system for pipeline risk assessment, Journal of Loss Prevention in the Process Industries, In Press.

Jang J.S., Sun C.T. (1997) Neuro fuzzy and soft computing: a computational approach to learning and machine intelligence, Prentice Hall, New Jersey, Englewood Cliffs. 
Karimi I., Hüllermeier E. (2007) Risk assessment system of natural hazards: A new approach based on fuzzy probability, Fuzzy Sets and Systems 158, 987-999.

Kentel E., Aral M.M. (2007) Risk Tolerance Measure for Fuzzy Health Risk Assessment, International Journal for Stochastic Environmental Research and Risk Assessment 21, 405-417.

Kirchsteiger C. (2005) Review of industrial safety management by international agreements and institutions, Journal of Risk Research 8, 31-51.

Kletz T.A. (1977) Unconfined Vapor cloud explosions, AICHE Loss Prevention 11, 50-61.

Lees F.P. (2001) Loss prevention in the process industries, hazard identification, assessments and control, 2nd ed., Butter WorthHeinemann, Oxford.

Li Z. (2006) Fuzzy chaotic systems: modeling, control, and applications, Springer, Germany.

Ma H.W. (2002) Stochastic multimedia risk assessment for a site with contaminated groundwater, Stochastic Environmental Research and Risk Assessment 16, 464-478.

Mamdani E.H. (1976) Advances in the linguistic synthesis of fuzzy controllers, International Journal of Man-Machine Studies 8, 669-678.

Mamdani E.H., Assilian S. (1975) An experiment in linguistic synthesis with a fuzzy logic controller, International Journal of Man-Machine Studies 7, 1-13.

Mark W., Cohen P.E., Glen R.P. (2004) Project risk identification and management, AACE International Transaction 01, 1-5.

Markowski A.S., Mannan M.S. (2008) Fuzzy risk matrix, Journal of Hazardous Materials 159, 152-157.

Markowski A.S., Mannan M.S. (2009a) Fuzzy logic for piping risk assessment, Journal of Loss Prevention in the Process Industries 22, 921-927.

Markowski A.S., Mannan M.S., Bigoszewska A. (2009b) Fuzzy logic for process safety analysis, Journal of Loss Prevention in the Process Industries 22, 695-702.

McKone T.E., Deshpande A.W. (2005) Can fuzzy logic bring complex environmental problems into focus? Environmental Science Technology 39, 42-47.

Modarres M. (2006) Risk analysis techniques, tools and trends, CRC Press, Florida.
Naderi M. (2008) Fuzzy logic application in risk analysis of construction management, M.S. Thesis, Dep. of Civil and Environmental Engineering, Alberta

Nieto-Morote A., Ruz-Vila F. (2011) A fuzzy approach to construction project risk assessment, International Journal of Project Management 29, 220-231.

OREDA (2009) Offshore Reliability Data Handbook, 5th ed., SINTEF Industrial Management, Norway.

OGP (2010) Report No. 434-1: Risk Assessment Data Directory: Process Release Frequencies, International Association of Oil and Gas Procedures.

Perry J.G., Hayes R.W. (1985) Risk and its management in construction projects, Proceeding of Institution Civil Engineers 78, 499-521.

POGC (2010) Pars Oil and Gas Company (POGC), report on general storage area in Assaluye and Tobmak in South Pars Industrial area, www.POGC.ir, Tehran.

Pokoradi L. (2002) Fuzzy logic based risk assessment, Academic and Applied Research in Military Science 1, 63-73.

Ross T.J. (2010) Fuzzy logic with engineering applications, 2nd ed., John Wiley and Sons, New York.

Uricchio V.F., Giordano R., Lopez N. (2004) A fuzzy knowledge based decision support for groundwater pollution risk evaluation, Journal of Environmental Management 73, 189-197.

Vemula V.R.S., Mujumdar P.P., Ghosh S. (2004) Risk evaluation in water quality management of a river system, Journal of Water Resources Planning and Management 130, 411-420.

Wulan M., Petrovic D. (2012) A fuzzy logic based system for risk analysis and elevation within enterprose collaborations, Computers in Industry 63, 739-748.

Xie M. (2003) Fundamentals of robotics: linking perception to action, World Scientific Publishing Co., London.

Zadeh L. (1965) Fuzzy sets, Information and Control 8, 338-353. Varnes D.J. (1984) Commissioning on landslides and other mass movements, IAEG. Landslide hazard zonation: a review of principles and practices, The UNESCO Press, Paris.

Manuscript submitted in February 2014 Manuscript accepted in September 2014 Published online in November 2014

Cite this article as: K. Karimpour, R. Zarghami, M.A. Moosavian and H. Bahmanyar (2014). New Fuzzy Model for Risk Assessment Based on Different Types of Consequences, Oil Gas Sci. Technol 71, 17. 